2 - ORIGINAL ARTICLE

WOUND HEALING

\title{
Adipose tissue stromal vascular fraction in the treatment of full thickness burns in rats ${ }^{1}$
}

\author{
Alexandre Lamaro CardosoI, Maria Márcia. Bachion", Júlia de Miranda Morais ${ }^{I I I}$, Marcelo Silva Fantinati ${ }^{\mathrm{IV}}$, Vera Lúcia Lima \\ de Almeidav , Ruy Souza Lino Júnior ${ }^{\mathrm{VI}}$ \\ DOI: http://dx.doi.org/10.1590/S0102-865020160090000002 \\ IFellow Master degree, Faculty of Medicine, Universidade Federal de Goiás (UFG), Goiania-GO, Brazil. Intellectual and scientific content of the study, \\ conception and design of the study, manuscript writing. \\ ${ }^{\text {II } P h D, ~ F u l l ~ P r o f e s s o r, ~ F a c u l t y ~ o f ~ N u r s i n g ~ U F G, ~ G o i a n i a-G O, ~ B r a z i l . ~ A c q u i s i t i o n, ~ a n a l y s i s ~ a n d ~ i n t e r p r e t a t i o n ~ o f ~ d a t a . ~}$ \\ IIIPhD, Associate Professor, Faculty of Medicine, UFG, Goiania-GO, Brazil. Acquisition, analysis and interpretation of data. \\ ${ }^{\text {IV }} \mathrm{PhD}$, Full Professor, ESEFFEGO, Universidade Estadual de Goiás (UEG), Goiania-GO, Brazil. Acquisition, analysis and interpretation of data. \\ vBiomedic, Institute of Tropical Pathology and Public Health, Experimental Pathology Laboratory, UFG, Goiania-GO, Brazil. Acquisition of data. \\ ${ }^{\mathrm{V}} \mathrm{PhD}$, Associate Professor, Institute of Tropical Pathology and Public Health, Experimental Pathology Laboratory, UFG, Goiania-GO, Brazil. Scientific \\ and intellectual content of the study, analysis and interpretation of data, statistical analysis, manuscript preparation.
}

\section{ABSTRACT}

PURPOSE: To analyze the healing effects of stromal vascular fraction (SVF) application compared to wound dressing with $2 \%$ silver sulfadiazine in full thickness burn wounds in rats.

METHODS: Animals were divided into two groups: 2\% silver sulfadiazine group and SVF group. Both groups received occlusive bandages while the first one was treated with $2 \%$ silver sulfadiazine and the latter was treated with injections of SVF prepared from adipose tissue extracted from an animal donor. The animals were accompanied through 3, 7 and 30 days for evaluation of macroscopic, microscopic and morphometric aspects.

RESULTS: On day three, a significant increase $(\mathrm{p}<0.05)$ of infiltration of polymorphonuclear, fibrin formation and fibroblasts migration in SVF group was observed. On the $7^{\text {th }}$ day the mononuclear infiltrate, angiogenesis, collagen and fibroblasts were significantly increased in the SVF group $(\mathrm{p}<0.05)$. At 30 days significantly increased collagen deposition was observed in the $\mathrm{SVF}$ group ( $\mathrm{p}<0.05$ ).

CONCLUSION: Adipose tissue derived stromal vascular fraction injections promotes better wound repair than $2 \%$ silver sulfadiazine in the treatment of full thickness burn in rats during the evaluated experimental period.

Key words: Burns. Wound Healing. Rats. 


\section{Introduction}

Full thickness burns are characterized by destruction of all skin layers. The destruction of the free nerve endings in the dermis makes these lesions painless, and grafting procedures are often needed to optimize tissue repair that usually evolves with formation of hypertrophic scars, severe fibrosis and tissue adhesion ${ }^{1}$.

The global incidence of burns requiring medical intervention in 2004 was about 11 million people. Although the majority of cases throughout the world are not fatal, fire related burns are among the leading causes of disability in low and middle income countries ${ }^{2}$.

The Brazilian Burn Society estimates that millions of burn cases occur every year in Brazil. Approximately two hundred thousand are treated at emergency wards and forty thousand require hospitalization. Estimates presented in a study conducted in the Federal District of Brazil showed a mortality rate of $6.2 \%$ among hospitalized burns victims in emergency wards. Among violent causes of death in Brazil burn injuries represent the third most important cause after road accidents and homicides ${ }^{3}$.

The techniques conventionally used in the treatment of burn wounds vary according to the extent of the lesion, affected body area, age and previous individual health status. Prevention of infections, removal of necrosis, and grafting procedures are routinely used to treat such wounds ${ }^{4}$.

In full thickness burn injuries surgical debridement followed by occlusive dressing are generally used in most clinical centers dedicated to the treatment of these lesions. Moisturizing agents such as glycerin and microbicides as $2 \%$ silver sulfadiazine are incorporated into the occlusive dressing to promote the healing process and prevent infection ${ }^{5}$.

While the outcomes in burn wound injury treatments increased significantly in the last decades, as a result of developments in surgical, nursing and rehabilitation procedures, severe functional and cosmetic limitations are still highly prevalent in burn patient populations ${ }^{6}$. The development of interventions to reduce hypertrophic scarring, promote morphological reconstruction and functional recovery are necessary in order to achieve better results?

Cell therapy is one of the most promising approaches to morphological reconstruction and functional restoration of skin burn damage. The effective application of cell populations that optimize the repair processes and tissue regeneration in different clinical conditions depends on several factors such as type of cell, cell cultivation techniques, injured tissue and patient's immune response $^{8}$. Of particular importance is the recognition of abundant sources of cells, with great therapeutic potential ${ }^{9}$.

The separation of adipose tissue components by enzymatic digestion and subsequent centrifugation of the material raised new possibilities for using this tissue in regenerative therapy. While initially the focus was turned to the use of mature adipocytes, located in the upper region of tissue solution after centrifugation, different studies have explored the therapeutic applications of stromal vascular fraction $(\mathrm{SVF})^{10}$.

Endothelial cells, lymphocytes, myelocytes, pericytes, pre-adipocytes and adipose derived stem cells (ADSCs) are part of its composition and, depending on the stimuli in the tissue microenvironment, present considerable plasticity, and the capacity to proliferate and differentiate into distinct cell lines ${ }^{11}$.

Studies suggest that therapeutic effects of SVF are primarily a result of the activity of $\mathrm{ADSCs}^{7,12}$ such as modulation of inflammatory response ${ }^{13}$, increased migration of fibroblasts ${ }^{14}$, collagen production ${ }^{15}$ an angiogenesis ${ }^{16-18}$.

Considering the need to develop interventions which address the reduction of fibrosis, restrictions in tissue mobility, aesthetic deformities and functional limitations in full thickness burn injuries, this study aimed to compare the microscopic, macroscopic and morphometric effects between the treatments with SVF applied intradermally and occlusive bandages with $2 \%$ silver sulfadiazine in experimentally induced full thickness burn wounds in rats.

\section{Methods}

The study was approved by the Ethics Committee on the use of animals from the Universidade Federal de Goiás (protocol Number 035/13).

\section{Stromal vascular fraction preparation and injection procedure}

One day after the burn procedure, euthanasia of the donor animal was performed (lethal injection of thiopental sodium $100 \mathrm{mg} / \mathrm{kg}$ ) followed by the removal of the visceral adipose tissue by surgical dissection. The material was conducted to laminar flux in transport solution (Sterile Phosphate Buffer Solution at 2\% (PBS) and 1\% antibiotics: 105 units $/ \mathrm{ml}$ penicillin and 105ug/ml streptomycin) washed in PBS to remove debris and red blood cells and minced with fine tissue scissors. The fragmented tissues were 
incubated with type I collagenase $(1.5 \mathrm{mg} / \mathrm{ml})$ and kept in water bath at $37^{\circ} \mathrm{C}$ for 50 minutes. After enzymatic digestion, the tissue was filtered using a $70 \mu \mathrm{m}$ filter and collagenase was removed by dilution with phosphate buffer solution (PBS). The cell suspension was centrifuged at $363 \mathrm{~g}(1800 \mathrm{rpm}) / 7$ minutes and the supernatant, composed primarily of mature adipocytes, was removed. The pellet was formed by cells which were re-suspended in PBS. The counting of viable cells was performed using the Tripan Blue stain exclusion method. Injections were prepared adding PBS and a $\mathrm{SVF}$ volume equivalent to $5 \times 10^{5}$ cells $/ \mathrm{ml}$ in $1 \mathrm{ml}$ syringes. Four injections of $0.2 \mathrm{ml}$ were made in each wound edge and dripping of $0.2 \mathrm{ml}$ covering the wound bed.

\section{Full thickness burn procedure}

After local preparation of the dorsal skin, shaving and antisepsis, the animals were anesthetized with $0.01 \mathrm{ml} / \mathrm{g}$ of Ketamine $10 \%$ and $0.03 \mathrm{ml} / \mathrm{g}$ of Xilazine $2 \%$ via intraperitoneal. Afterwards, the full thickness thermal injury was induced by the immersion of this region in boiling water as described by Morais et al. ${ }^{19}$. Briefly, each animal was placed inside a PVC (polyvinyl chloride) plastic cylinder with a $2 \times 2 \mathrm{~cm}$ opening and sealed extremities, the uncovered area was immersed in water at $95^{\circ}$ for 14 seconds. The accomplishment of a full thickness burn by the cited method was early verified by histological analysis with hematoxylin-eosin preparation showing complete destruction of the epidermis, dermis and hypodermis confirming a full thickness burn wound with necrosis and disarrangement of collagen fibers. On the day that followed the burn procedure, animals received surgical debridement under general anesthesia $(0.06 \mathrm{ml} / \mathrm{Kg}$ of $10 \%$ ketamine, $0.01 \mathrm{ml} / \mathrm{Kg}$ distilled water and $0.03 \mathrm{ml} / \mathrm{Kg}$ of $2 \%$ xylazine applied intraperitoneally) to remove necrosis. Debridement procedure initiated by dissection of skin with a Metzembaum scissor in panniculus carnosum, at the suprafascial level. The other edges were sectioned with a straight Mayo scissor always in the internal border of demarcated area. A full thickness skin $\left(4 \mathrm{~cm}^{2}\right)$ was excised from burn area by removing the epidermis and dermis layer with a surgical blade $(0.1 \mathrm{~mm})$ until the subcutaneous fat,avoiding the panniculus carnosum and the muscle layer. Early post operative and three days post burn pain management was performed by inclusion of $2 \mathrm{mg} / \mathrm{ml}$ paracetamol in the rats' drinking water.

\section{Animals and treatment}

Thirty male adult Wistar rats weighing between 300 and $350 \mathrm{~g}$ were used in this study. Adipose tissue extraction was made once in each experimental series with durations of 3, 7 and 30 days, with a total of three animals used as donors. Each experimental group was composed by five animals. Each experimental group received treatment after the debridement procedure, 2 days after the injury induction. The $2 \%$ silver sulfadiazine group (CT) received occlusive bandages with sterile gauze impregnated with glycerine and $2 \%$ silver sulfadiazine. The stromal vascular fraction treated group (SVF) received occlusive bandages with sterile gauze impregnated with glycerine and injections of stromal vascular fraction at a concentration of $5 \times 10^{5}$ cells $/ \mathrm{ml}$. The injection procedure was made only once after debridement in SVF group and bandages were change in each group daily during the experimental series.

The animals euthanasia was performed at each experimental day with a lethal injection of thiopental sodium $100 \mathrm{mg} / \mathrm{kg}$ followed by collection of material for microscopic examination and photographic register of the injury for morphometric and macroscopic analysis.

\section{Macroscopic evaluation}

After euthanasia, wounds were photographed and the component phases of tissue repair such as inflammation, proliferation and maturation ${ }^{19}$ were macroscopically examined. Parameters of hyperemia, necrosis, hemorrhage, crust formation, tissue granulation and fibrosis were graded as absent (score 0), discrete (up to $25 \%$ of committed area, score 1), moderate (from 26 to $50 \%$ of committed area, score 2) and accentuated (more than $50 \%$ of committed area, score 3 ) in a semi-quantitative form. Examination was performed by the same researcher, blind to group allocation. The results were expressed in mean \pm standard deviation.

\section{Morphometric evaluation}

Wound photographs were analyzed using the ImageJ software (National Institute of Health; version 1.3.1). Wound areas were circulated by the researcher without knowing the group allocation, and the contraction level was calculated using the following equation:

$$
\mathrm{CL}=\left(\text { area } \mathrm{T}^{0}-\text { area } \mathrm{T}^{\text {euthanasia day }}\right) \mathrm{x} \quad 100 / \text { area } \mathrm{T}^{0} \text {,were }
$$
$\mathrm{CL}=$ contraction level; $\mathrm{T}^{0}=$ day of burn injury induction; $\mathrm{T}^{\text {euthanasia }}$ 
day $=$ days after injury induction. The morphometric evaluation was performed at days 7 and 30 due to the absence of wound contraction at the early stage of the healing process ( 3 days).

\section{Microscopic evaluation}

After euthanasia, the wound tissue and adjacent skin were removed. This material was incubated with $10 \%$ formaldehyde, included in paraffin blocks, prepared with sections of $4 \mu \mathrm{m}$ and stained with hematoxylin-eosin (H\&E). Tissue slides were analyzed by optical microscopy of entire wound area at magnifications of $\mathrm{x} 10$ and $\mathrm{x} 40$ and parameters of fibrin, hemorrhage, polymorphonuclear infiltration, mononuclear infiltration, hyperemia, angiogenesis, necrosis, fibroblasts and collagen were graded as absent (score 0), discrete (up to $25 \%$ of committed area, score 1), moderate (from 26 to $50 \%$ of committed area, score 2) and accentuated (more than $50 \%$ of committed area, score 3 ) in a semi-quantitative form. Examination was performed by the same researcher, blind to group allocation. The results were expressed in mean \pm standard deviation.

\section{Statistical analysis}

Statistical analysis was performed with the SigmaStat 2.3 software. Variables were tested for normal distribution and homogeneous variance (Kolmogorov-Smirnov test). The macroscopic and microscopic statistical analyses were performed through the Mann-Whitney test. The morphometric analysis was performed through the Student T test. Differences were considered significant when $\mathrm{p}<0.05$.

\section{Results}

\section{Macroscopic results}

General pathologic process associated with inflammation, proliferation and maturation phases were observed in days 3, 7 and 30 respectively (Figure 1). Statistically significant differences were found between the CT group and SVF group regarding necrosis formation, which was significantly increased in the CT group at day $3(\mathrm{p}<0.05)$. Other parameters such as crust, hemorrhage, hyperemia, granulation tissue and fibrosis did not present a macroscopic difference when comparing both treatments (Table 1).

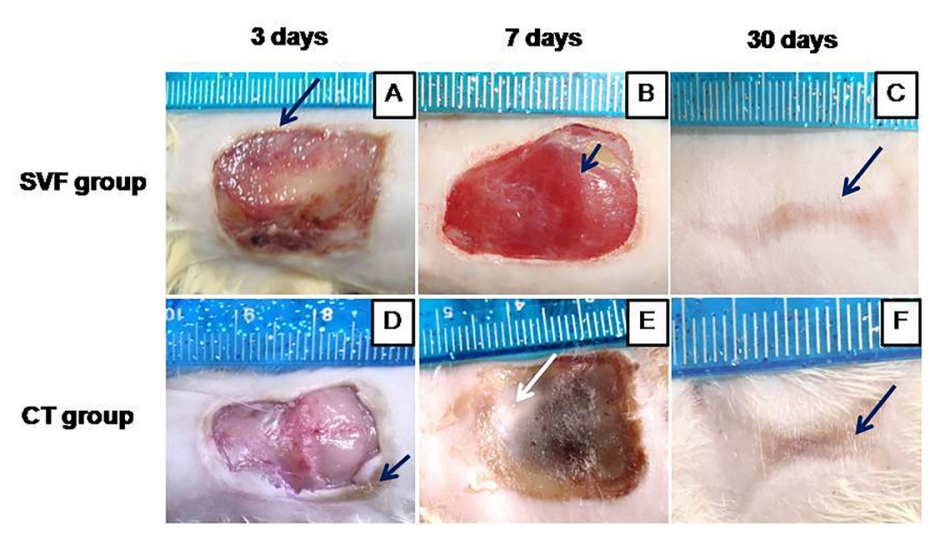

FIGURE 1 - Macroscopic evaluation of third degree burn wounds experimentally induced in rats treated with $2 \%$ silver sulfadiazine and adipose tissue stromal vascular fraction. (CT - control group) $2 \%$ silver sulfadiazine. (SVF) adipose tissue stromal vascular fraction treated group. (A) Arrow indicates discrete hyperemia. (B) Arrow indicates accentuated granulation tissue. (C) Arrow indicates discrete fibrosis. (D) Arrow indicates accentuated necrosis at wound edges. (E) Arrow indicates moderate necrosis. (F) Arrow indicates accentuated fibrosis.

TABLE 1 - Macroscopic evaluation (mean \pm standard deviation) of general pathological processes in third degree burn wound in rats treated with $2 \%$ silver sulfadiazine and adipose tissue stromal vascular fraction at days 3, 7 and 30 .

\begin{tabular}{ccccc}
\hline $\begin{array}{c}\text { Pathological } \\
\text { Process }\end{array}$ & DAI & $\begin{array}{c}\mathbf{C T} \\
(\mathbf{n}=\mathbf{5})\end{array}$ & $\begin{array}{c}\text { SVF } \\
\mathbf{( n = 5 )}\end{array}$ & $\mathbf{P}$ \\
\hline Necrosis & $\mathbf{3}$ & $1.0 \pm 0.6$ & $0.3 \pm 0.8$ & $\mathbf{p}=\mathbf{0 . 0 1}$ \\
& $\mathbf{3 0}$ & $0.3 \pm 0.6$ & $1.3 \pm 0.4$ & $\mathrm{p}=0.183$ \\
& $\mathbf{3}$ & $0.3 \pm 0.6$ & $0.0 \pm 0.0$ & $\mathrm{p}=1.00$ \\
Crust & $\mathbf{7}$ & $0.3 \pm 0.6$ & $0.0 \pm 0.0$ & $\mathrm{p}=0.183$ \\
& $\mathbf{3 0}$ & $0.0 \pm 0.0$ & $0.0 \pm 0.0$ & $\mathrm{p}=1.00$ \\
Hemorrhage & $\mathbf{7}$ & $0.3 \pm 0.6$ & $1.3 \pm 0.4$ & $\mathrm{p}=0.183$ \\
& $\mathbf{3 0}$ & $0.0 \pm 0.0$ & $0.0 \pm 0.0$ & $\mathrm{p}=1.00$ \\
Hyperemia & $\mathbf{3}$ & $0.3 \pm 0.6$ & $2.6 \pm 0.4$ & $\mathrm{p}=0, .57$ \\
& $\mathbf{3 0}$ & $0.0 \pm 0.0$ & $0.0 \pm 0.0$ & $\mathrm{p}=1.00$ \\
Granulation & $\mathbf{3}$ & $0.0 \pm 0.0$ & $0.0 \pm 0.0$ & $\mathrm{p}=1.00$ \\
tissue & $\mathbf{7}$ & $0.3 \pm 0.6$ & $2.6 \pm 0.4$ & $\mathrm{p}=0.057$ \\
& $\mathbf{3 0}$ & $0.3 \pm 0.6$ & $0.0 \pm 0.0$ & $\mathrm{p}=1.00$ \\
& $\mathbf{3}$ & $0.0 \pm 0.0$ & $0.0 \pm 0.0$ & $\mathrm{p}=1.00$ \\
Fibrosis & $\mathbf{7}$ & $0.0 \pm 0.0$ & $0.0 \pm 0.0$ & $\mathrm{p}=1.00$ \\
& $\mathbf{3 0}$ & $3.0 \pm 0.0$ & $3.0 \pm 0.0$ & $\mathrm{p}=1.00$ \\
\hline
\end{tabular}

SVF: stromal vascular fraction group. CT: $2 \%$ silver sulfadiazine group. n: number of animals in each group. DAI: days after injury induction. *Statistically significant $(\mathrm{p}<0.05$ - Mann-Whitney). 


\section{Microscopic results}

Fibrin formation, polymorphonuclear infiltration and fibroblast content were significantly increased in the SVF group compared to the CT group at day $3(\mathrm{p}<0.05)$ (Figure 2$)$. The mononuclear infiltration, angiogenesis, fibroblast content and collagen deposition were significantly increased in the SVF group compared to the CT group at day $7(\mathrm{p}<0.05) .30$ days after burn injury induction hyperemia and collagen deposition were significantly increased in the SVF group compared to the CT group $(\mathrm{p}<0.05)($ Table 2$)$. Collagen disruption and hemorrhage did not present significant differences between the treated groups during the experimental days.

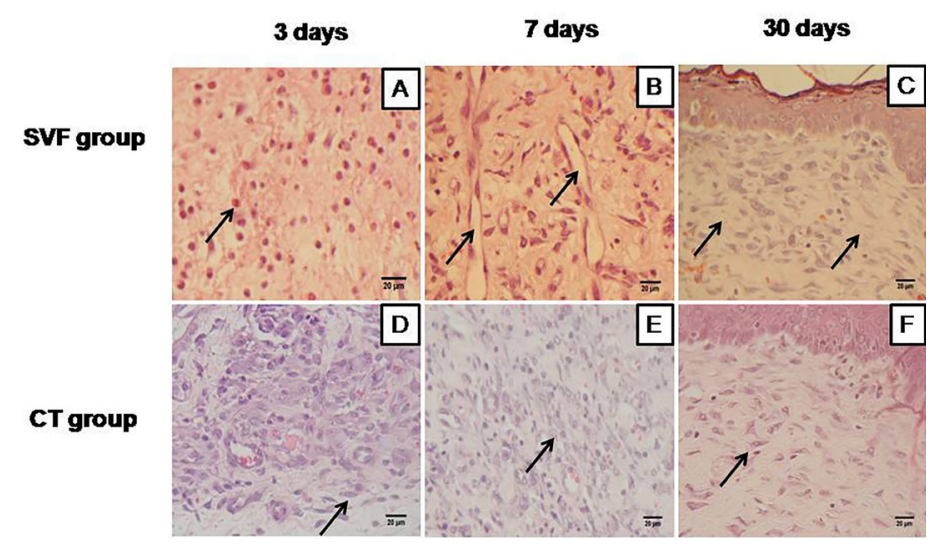

FIGURE 2 - Microscopic evaluation of third degree burn wounds experimentally induced in rats treated with $2 \%$ silver sulfadiazine and adipose tissue stromal vascular fraction. (CT - control group) $2 \%$ silver sulfadiazine. (SVF) adipose tissue stromal vascular fraction treated group. (A) Arrow indicates moderate fibroblastic proliferation. (B) Arrows indicate accentuated angiogenesis. (C) Arrows indicate accentuated collagen formation. (D) Arrow indicates discrete polymorphonuclear cells inflammatory infiltration. (E) Arrow indicates accentuated mononuclear cells inflammatory infiltration. (F) Arrow indicates moderate mononuclear cells inflammatory infiltration (x400 hematoxylin \& eosin. Scale Bar indicates $20 \mu \mathrm{m})$.
TABLE 2 - Microscopic evaluation (mean \pm standard deviation) of general pathological process in third degree burn wound in rats treated with $2 \%$ silver sulfadiazine and adipose stromal vascular fraction at days 3, 7 and 30 .

\begin{tabular}{|c|c|c|c|c|}
\hline $\begin{array}{c}\text { Pathological } \\
\text { Process }\end{array}$ & DAI & $\mathrm{CT}(\mathrm{n}=5)$ & $\operatorname{SVF}(n=5)$ & $\mathbf{P}$ \\
\hline \multirow{3}{*}{$\begin{array}{c}\text { Collagen } \\
\text { disruption }\end{array}$} & 3 & $3.0 \pm 0.0$ & $3.0 \pm 0.0$ & $\mathrm{p}=1.00$ \\
\hline & 7 & $1.0 \pm 0.0$ & $0.3 \pm 0.6$ & $\mathrm{p}=0.183$ \\
\hline & 30 & $0.6 \pm 0.5$ & $0.0 \pm 0.0$ & $\mathrm{p}=0.422$ \\
\hline \multirow{3}{*}{ Hemorrhage } & 3 & $0.0 \pm 0.0$ & $0.0 \pm 0.0$ & $\mathrm{p}=1.00$ \\
\hline & 7 & $1.8 \pm 0.7$ & $1.0 \pm 0.0$ & $\mathrm{p}=0.183$ \\
\hline & 30 & $0.2 \pm 0.4$ & $0.3 \pm 0.4$ & $\mathrm{p}=1.00$ \\
\hline \multirow{3}{*}{ Hyperemia } & 3 & $1.6 \pm 0.4$ & $1.6 \pm 0.9$ & $\mathrm{p}=0.741$ \\
\hline & 7 & $0.6 \pm 0.8$ & $2.0 \pm 0.81$ & $\mathrm{p}=0.225$ \\
\hline & 30 & $0.2 \pm 0.4$ & $2.0 \pm 0.0$ & $\mathrm{p}=\mathbf{0 . 0 3} *$ \\
\hline \multirow{3}{*}{ Fibrin } & 3 & $0.3 \pm 0.6$ & $3.0 \pm 0.0$ & $\mathrm{p}=0.03 *$ \\
\hline & 7 & $0.0 \pm 0.0$ & $0.0 \pm 0.0$ & $\mathrm{p}=1.00$ \\
\hline & 30 & $0.0 \pm 0.0$ & $0.0 \pm 0.0$ & $\mathrm{p}=1.00$ \\
\hline \multirow{3}{*}{$\begin{array}{l}\text { PMN infiltra- } \\
\text { tion }\end{array}$} & 3 & $0.0 \pm 0.0$ & $1.6 \pm 0.4$ & $\mathrm{p}=\mathbf{0 . 0 3} *$ \\
\hline & 7 & $0.6 \pm 1.2$ & $1.0 \pm 0.0$ & $\mathrm{p}=1.00$ \\
\hline & 30 & $0.0 \pm 0.0$ & $0.0 \pm 0.0$ & $\mathrm{p}=1.00$ \\
\hline \multirow{3}{*}{$\begin{array}{l}\text { MN infiltra- } \\
\text { tion }\end{array}$} & 3 & $0.6 \pm 0.48$ & $1.0 \pm 0.0$ & $\mathrm{p}=0.183$ \\
\hline & 7 & $0.6 \pm 0.4$ & $3.0 \pm 0.0$ & $\mathrm{p}=0.01 *$ \\
\hline & 30 & $0.8 \pm 0.7$ & $2.0 \pm 0.0$ & $\mathrm{p}=0.183$ \\
\hline \multirow{3}{*}{ Angiogenesis } & 3 & $0.0 \pm 0.0$ & $1.3 \pm 0.4$ & $\mathrm{p}=0.057$ \\
\hline & 7 & $0.3 \pm 0.6$ & $3.0 \pm 0.0$ & $\mathrm{p}=0.01 *$ \\
\hline & 30 & $0.3 \pm 0.6$ & $2.0 \pm 0.0$ & $\mathrm{p}=1.00$ \\
\hline \multirow{3}{*}{ Fibroblast } & 3 & $0.3 \pm 0.6$ & $2.0 \pm 0.0$ & $\mathrm{p}=0.03 *$ \\
\hline & 7 & $0.3 \pm 0.6$ & $2.0 \pm 0.0$ & $\mathrm{p}=\mathbf{0 . 0 3} *$ \\
\hline & 30 & $0.3 \pm 0.6$ & $3.0 \pm 0.0$ & $\mathrm{p}=0.42$ \\
\hline \multirow{3}{*}{ Collagen } & 3 & $0.0 \pm 0.0$ & $0.0 \pm 0.0$ & $\mathrm{p}=1.00$ \\
\hline & 7 & $0.3 \pm 0.6$ & $2.0 \pm 0.0$ & $p=0.03 *$ \\
\hline & 30 & $0.3 \pm 0.6$ & $3.0 \pm 0.0$ & $p=0.03 *$ \\
\hline
\end{tabular}

SVF: stromal vascular fraction group. CT: $2 \%$ silver sulfadiazine group. PMN:plymorphonuclear cells; MN: mononuclear cells. DAI: days after injury induction. *Statistically significant ( $\mathrm{p}<0.05$ - Mann-Whitney).

\section{Morphometric results}

No significant difference was observed between the SVF group and the CT group regarding the wound contraction levels at days 7 and 30 (Table 3). 
TABLE 3 - Morphometric evaluation of wound contraction area in third degree burn wound in rats treated with $2 \%$ silver sulfadiazine and adipose tissue stromal vascular fraction at days 7 and 30. Results expressed in percentage \pm standard deviation.

\begin{tabular}{ccc}
\hline Experimental group & 7 DAI & 30 DAI \\
\hline CT & $14.476 \pm 0.4$ & $88.207 \pm 2.6$ \\
SVF & $15.023 \pm 0.5$ & $88.203 \pm 5.8$ \\
p & $\mathrm{p}=0.676$ & $\mathrm{p}=0.149$ \\
\hline
\end{tabular}

CT: $2 \%$ silver sulfadiazine group. SVF: stromal vascular fraction group. DAI: days after injury induction. Statistical analysis: Student $\mathrm{T}$ test.

\section{Discussion}

This study demonstrated that the stromal vascular fraction removed from the adipose tissue improved the microscopic and macroscopic aspects of the healing process of full thickness burn wounds experimentally induced in rats. These improvements were observed in all phases of the healing process, inflammatory, proliferative and maturation.

Stromal vascular fractions are composed of different cell populations such as mesenchymal stem cells, T regulatory cells, endothelial precursor cells, preadipocytes and macrophages. All of them are capable of influencing the wound microenvironment in many ways as they share similarities with bone marrow stromal cells, including the capacity of multilineage differentiation ${ }^{20}$.

In this study, an amplification of the inflammatory response evidenced by increased migration of polymorphonuclear and fibrin deposition was observed at day 3. Studies applying SVF or ADSCs previously expanded in culture on wound models observed a reduction of the inflammatory response ${ }^{21}$. These different observations suggest that SVF could modulate inflammation in a bi-directional manner.

Studies have shown that controlled amplification of initial inflammatory episodes has been associated with a shift in repair processes of different tissues towards more regeneration and less scar formation ${ }^{22-24}$.

Trials designed to elucidate how different SVF preparations influence burn wound repair, regarding the type of adipose tissue utilized and dose-response curves for application of different SVF concentrations are needed to clarify the reasons for variable experimental findings.

A significant increase of fibrin and fibroblasts in the SVF group compared to the CT group at day 3 was also observed. Evidence suggests that fibronectin binding to fibrin $^{25}$ and ADSCs paracrine secretion of growth factors such as platelet derived growth factor (PDGF) and basic fibroblast growth factor (bFGF) could be possible associated mechanisms leading to the observed effect ${ }^{26}$.

At day 7 , angiogenesis $(p=0.01)$, fibroblasts $(p=0.03)$, mononuclear infiltrate $(p=0.01)$ and collagen production $(\mathrm{p}=0.03)$ showed a marked increase in the SVF group when compared to the control group at the same experimental day. The secretome repertoire of ADSCs has been reported to be composed by many cytokines and growth factors which are able to influence these parameters $^{12}$. Expression of potent angiogenic agents such as vascular endothelial growth factor (VEGF), fibroblast migration and activity stimulators like Transforming Growth Factor (TGF) and macrophages chemotaxis agents were expressed by ADSCs in studies performed in different models ${ }^{8,14}$. Collectively, this process could accelerate the proliferative phase and build better conditions for wound repair as observed in our results.

Regarding mononuclear infiltration, classically activated macrophages have been known to express high levels of pro-inflammatory cytokines like IL-1, IL-6 and IL23 and under its influence, Th17 cells have released IL-17 which induces increased recruitment of polymorphonuclear cells towards the injury $\operatorname{site}^{24}$. It was possible to observe an increase in the mononuclear infiltration at day 7 with no increase in polymorphonuclear infiltration. This result suggested that the cytokines released by SVF cells could change the macrophage activation profile from classic to regulatory which improved the wound healing profile. Corroborating this hypothesis is the observation of marked collagen formation in the SVF group. Activated regulatory macrophages have been known to increase the production of extracellular matrix components and the release of anti-inflammatory cytokines such as IL-10, controlling the extension and intensity of inflammation, therefore promoting better conditions for the occurrence of the proliferative process ${ }^{24}$.

Similarities between ADSCs in vivo morphology and fibroblasts could also contribute to the observation of increased fibroblast. Histological preparations with $\mathrm{H} \& \mathrm{E}$ did not allow the differentiation between the two cell types, nor the detection of fibroblasts that differentiate directly from $\mathrm{ADSCs}^{27}$.

The initial stimulation of fibroblasts at 3 and 7 DAI in the SVF treated group resulted in increased collagen deposition at day 30 . These results are in accordance to the 
description that ADSCs up-regulate type I and III collagen and fibronectin and down-regulate metalloproteinase 1(MMP-1), significantly accelerating healing from the wound edges and increasing the tensile strength of scar tissue $^{28}$. Studies approaching scar tissue tensile strength in burn wounds treated with SVF and isolated ADSCs could better elucidate the specific contributions of these different cell populations regarding the functional outcomes in the burn wound healing process and guidance of the clinical decision-making process about which procedure would have a better cost-benefit relationship.

SVF acquisition in humans using procedures such as lipoaspiration have been reported as a method that does not cause marked morbidity and have been easy to apply, particularly in conditions requiring immediate medical interventions such as in burn injuries ${ }^{18}$.

\section{Conclusions}

Intradermally applied SVF have improved full thickness burn wound healing in rats when compared to occlusive bandages with $2 \%$ silver sulfadiazine through amplification of the initial inflammatory episode, have increased fibroblast migration and collagen production. The improved wound healing process observed in this study showed that therapeutic application of cells extracted from adipose tissue could have a significant role in burn wound care.

\section{References}

1. Warner PM, Coffee TL, Yowler CJ. Outpatient burn management. Surg Clin North Am. 2014;94:879-92. doi: 10.1016/j. suc.2014.05.009.

2. Peck MD. Epidemiology of burns throughout the world. Part I: Distribution and risk factors. Burns. 2011;37:1087-100. doi: 10.1016/j.burns.2011.06.005.

3. Vale ECS. Inicial management of burns: approach by dermatologists. An Bras Dermatol. 2005;80:9-19. doi: 10.1590/ S0365-05962005000100003.

4. Sheridan RL. Special problems in burns. Surg Clin North Am. 2014;94:781-91. doi: 10.1016/j.suc.2014.05.002.

5. Wolf SE, Tompkins RG, Herndon DN. On the horizon: research priorities in burns for the next decade. Surg Clin North Am. 2014;94:917-30. doi: 10.1016/j.suc.2014.05.012.

6. Tredget EE, Levi B, Donelan MB. Biology and principles of scar management and burn reconstruction. Surg Clin North Am. 2014;94:793-815. doi: 10.1016/j.suc.2014.05.005.

7. You HJ, Han SK. Cell therapy for wound healing. J Korean Med Sci. 2014;29:311-9. doi: 10.3346/jkms.2014.29.3.311.

8. Cherubino M, Rubin JP, Miljkovic N, Kelmendi-Doko A, Marra KG Adipose-derived stem cells for wound healing applications. Ann Plast Surg. 2011;66:210-5. doi: 10.1097/SAP.0b013e3181e6d06c.
9. Gimble JM, Guilak F, Bunnell BA. Clinical and preclinical translation of cell-based therapies using adipose tissue-derived cells. Stem Cell Res Ther. 2010;1:19. doi: 10.1186/scrt19.

10. Tabit CJ, Slack GC, Fan K, Wan DC, Bradley JP. Fat grafting versus adipose-derived stem cell therapy: distinguishing indications, techniques, and outcomes. Aesthetic Plast Surg. 2012;36:704-13. doi: 10.1007/s00266-011-9835-4.

11, Gentile P, Orlandi A, Scioli MG, Di Pasquali C, Bocchini I, Cervelli V. Concise review: adipose-derived stromal vascular fraction cells and platelet-rich plasma: basic and clinical implications for tissue engineering therapies in regenerative surgery. Stem Cells Transl Med. 2012;1:230-6. doi: 10.5966/sctm.2011-0054.

12. Kapur SK, Katz AJ. Review of the adipose derived stem cell secretome. Biochimie. 2013;95:2222-8. doi: 10.1016/j. biochi.2013.06.001.

13. Lee $\mathrm{SH}$, Lee JH, Cho KH. Effects of human adipose-derived stem cells on cutaneous wound healing in nude mice. Ann Dermatol. 2011;23:150-5. doi: 10.5021/ad.2011.23.2.150.

14. Kokai LE, Marra K, Rubin JP. Adipose stem cells: biology and clinical applications for tissue repair and regeneration. Transl Res. 2014;163:399-408. doi: 10.1016/j.trsl.2013.11.009.

15. Lim JS, Yoo G. Effects of adipose-derived stromal cells and of their extract on wound healing in a mouse model. J Korean Med Sci. 2010;25:746-51. doi: 10.3346/jkms.2010.25.5.746.

16. Wang X, Liu C, Li S, Xu Y, Chen P, Liu Y, Ding Q, Wahafu W, Hong B, Yang M. Hypoxia precondition promotes adipose-derived mesenchymal stem cells based repair of diabetic erectile dysfunction via augmenting angiogenesis and neuroprotection. PLoS One. 2015;10:e118951. doi: 10.1371/journal.pone.0118951.

17. Uysal CA, Tobita M, Hyakusoku H, Mizuno H. The effect of bonemarrow-derived stem cells and adipose-derived stem cells on wound contraction and epithelization. Adv Wound Care. 2014;3:405-13. doi: 10.1089/wound.2014.0539.

18. Atalay S, Coruh A, Deniz K. Stromal vascular fraction improves deep partial thickness burn wound healing. Burns. 2014;40:137583. doi: 10.1016/j.burns.2014.01.023.

19. Broughton G, Janis JE, Attinger CE. The basic science of wound healing. Plast Reconstr Surg. 2006;117:12S-34S. doi: 10.1097/01. prs.0000225430.42531.c2.

20. Fraser JK, Hicok KC, Shanahan R, Zhu M, Miller S, Arm DM. The Celution ${ }^{\circledR}$ system: automated processing of adipose-derived regenerative cells in a functionally closed system. Adv Wound Care. 2014;3:38-45. doi: 10.1089/wound.2012.0408.

21. Gentile P, De Angelis B, Pasin M, Cervelli G, Curcio CB, Floris M, Di Pasquali C, Bocchini I, Balzani A, Nicoli F, Insalaco C, Tati E, Luarini L, Palla L, Pascali M, De Logu P, Di Segni C, Bottini DJ, Cervelli V. Adipose-derived stromal vascular fraction cells and platelet-rich plasma: basic and clinical evaluation for cellbased therapies in patients with scars on the face. J Craniofac Surg. 2014;25:267-72. doi: 10.1097/01.scs.0000436746.21031.ba.

22. Wada K, Arita M, Nakajima A, Katayama K, Kudo C, Kamisaki Y, Serhan CN. Leukotriene B4 and lipoxin A4 are regulatory signals for neural stem cell proliferation and differentiation. FASEB J. 2006;20:1785-92. doi:0.1096/fj.06-5809com.

23. Kyritsis N, Kizil C, Zocher S, Kroehne V, Kaslin J, Freudenreich D, Iltzsche A, Brand M. Acute inflammation initiates the regenerative response in the adult zebrafish brain. Science. 2012;338:1353-6. doi: 10.1126/science.1228773.

24. Gourevitch D, Kossenkov AV, Zhang Y, Clark L, Chang C, Showe LC,Heber-Katz E. Inflammation and its correlates in regenerative wound healing: an alternate perspective. Adv Wound Care. 2014;3:592-603. doi: 10.1089/wound.2014.0528. 
25. Bainbridge P. Wound healing and the role of fibroblasts. J Wound Care. 2013;22:407-8, 410-2. doi: 10.12968/jowc.2013.22.8.407.

26. Kim WS, Park BS, Sung JH. Protective role of adipose-derived stem cells and their soluble factors in photoaging. Arch Dermatol Res. 2009;301:329-36. doi: 10.1007/s00403-009-0951-9.

27. Harasymiak-Krzyżanowska I, Niedojadło A, Karwat J, Kotuła L, Gil-Kulik P, Sawiuk M,Kocki J. Adipose tissue-derived stem cells show considerable promise for regenerative medicine applications. Cell Mol Biol Lett. 2013;18:479-93. doi: 10.2478/s11658-0130101-4.

28. Kim WS, Park BS, Sung JH, Yang JM, Park SB, Kwak SJ,Park JS Wound healing effect of adipose-derived stem cells: a critical role of secretory factors on human dermal fibroblasts. J Dermatol Sci. 2007;48:15-24. doi: 10.1016/j.jdermsci.2007.05.018.

\section{Acknowledgement}

To Vânia Beatriz Lopes for help in technical analysis.

\section{Correspondence:}

AlexandreLamaro Cardoso

Faculdade de Medicina - UFG

Rua 235,1 a s/n, Setor Universitário

Goiânia-GO Brasil

Tel/Fax: (55 62)3209-6165

alexandrelamaro@hotmail.com

Received: May 21, 2016

Review: July 19, 2016

Accepted: Aug 18, 2016

Conflict of interest: none

Financial source: FAPEG (grant number 2013/0267001091)

${ }^{1}$ Research performed at Laboratory of Experimental Pathology, Institute of Tropical Pathology and Public Health, Universidade Federal de Goiás (UFG), Goiania-GO, Brazil. 